\title{
INCLUSÃO NA EDUCAÇÃO FÍSICA ESCOLAR: estudo da tríade acessibilidade-conteúdos-atitudes
}

\author{
Camila Lopes de Carvalho' \\ Marina Brasiliano Salerno² \\ Rita de Fátima da Silva ${ }^{3}$ \\ Paulo Ferreira de Araújo ${ }^{4}$
}

\section{RESUMO}

A educação inclusiva foi consolidada legalmente, mas tem apresentado dificuldades para se efetivar na realidade. Assim, esse estudo objetiva analisar a percepção dos docentes de Educação Física das escolas de Franca/SP acerca da forma como têm vivenciado a inclusão durante sua prática profissional. Foi desenvolvido um estudo de caso, no qual os docentes responderam ao "Instrumento de avaliação da interação entre alunos com e sem deficiência na Educação Física Escolar", com dados analisados por categorização. Observou-se uma trajetória ambígua com pontos facilitadores, com professores se propondo a elaborar aulas adequadas a todos, alternando-se com elementos dificultadores, como a falta de reflexão e diálogo. Há uma construção positiva com apontamentos para possíveis reorganizações da atuação docente segundo as novas propostas acadêmicas sobre a inclusão educacional e também sobre a Educação Física Escolar.

Palavras-chave: Educação Física e treinamento. Pessoas com deficiência. Inclusão educacional

1 Doutoranda em Educação Física. Faculdade de Educação Física da Universidade Estadual de Campinas (FEF/ UNICAMP). Campinas/ São Paulo, Brasil. E-mail: camilalopes.c@hotmail.com

2 Doutora em Educação Física. Professora na Universidade Federal de Mato Grosso do Sul (UFMS). Campo Grande/Mato Grosso do Sul, Brasil. E-mail: marina.brasiliano@gmail.com

3 Doutora em Atividade Física Adaptada. Professora na Universidade Federal de Mato Grosso do Sul (UFMS). Ponta Porã/Mato Grosso do Sul, Brasil. E-mail: rita_fatima@hotmail.com

4 Doutor em Educação Física. Professor na Universidade Estadual de Campinas (UNICAMP). Campinas/São Paulo, Brasil. E-mail: paulof@fef.unicamp O presente trabalho não contou com apoio financeiro de nenhuma natureza para sua realização. Não há conflitos de interesse na elaboração deste manuscrito. 


\title{
STUDENTS WITH DISABILITIES INCLUSION IN SCHOOL PHYSICAL EDUCATION:
} the look of teachers on construction process inclusive

\begin{abstract}
The educational inclusion have difficulties during the execution of this process. This study aims to analyze the inclusive process in physical education classes in public schools in Franca, São Paulo, from the look of the teachers of this discipline. A case study was developed, where physical education teachers this school system met the "evaluation tool of interaction between students with and without disabilities in physical education", Salerno, Araújo e Silva (2009), with data analyzed by categorization. There was a time of transition with facilitators points with teachers intending to develop appropriate lessons to all, alternating with complicating factors such as student infantilization with disabilities. There is a positive construction with notes for possible reorganizations of the performance according to the new academic proposals on educational inclusion and also on School Physical Education.
\end{abstract}

Keywords: Physical Education and training. Disabled persons. Inclusive education

\section{ESTUDIANTES CON DISCAPACIDAD EN LA INCLUSIÓN EDUCACIÓN FÍSICA ESCOLAR: el aspecto de los profesores en proceso de construcción inclusiva}

\section{RESUMEN}

La educación inclusiva ha tenido dificultades para consolidar. Nuestro objetivo fue analizar en la perspectiva de los docentes de esa área en escuelas en la ciudad de Franca/SP, cómo la inclusión ha sido vivida en su práctica rutinera. Desarrollamos un estudio de caso, en que los maestros de educación física rellenaron la "Herramienta de evaluación de la interacción entre alumnos con y sin discapacidad en la educación física", los datos fueron analizados por la categorización. Observamos una trayectoria ambigua con puntos facilitadores, como los maestros elaborando sus clases adecuadas a todos los alumnos; y elementos dificultadores como la falta de reflexión y dialogo. Hay una construcción positiva con notas para una posible reorganización de la práctica docente de acuerdo con las nuevas propuestas académicas sobre la inclusión educativa y también en Educación Física en la Escuela.

Palabras clave: Educación y entrenamiento físico. Personas con discapacidad. Educación inclusiva 


\section{INTRODUÇÃO}

A Educação Física enquanto componente curricular do sistema educacional básico nacional tem por finalidade a construção de conhecimentos a respeito do corpo e suas possibilidades de movimento, considerando as múltiplas dimensões humanas, como a afetiva, bio-física e psicológica, além do contexto histórico, social, cultural e político-econômico no qual se insere. Para o desempenho dessa função, o docente foi incumbido de elaborar aulas que permitam a participação de todos, adaptando as atividades de forma a estimular as potencialidades de cada aluno, independente das diferenças que os mesmos possam apresentar (COLETIVO DE AUTORES, 1992; BRASIL, 1998).

A Educação Física Escolar vigente foi encarregada de se estabelecer por embasamentos inclusivos, sendo a efetivação de sua prática segundo as definições acadêmicas e políticas estabelecidas, acima apresentadas, dependente da superação de um passado de rejeições e exclusões.

Rememorando brevemente esse contexto, podemos apontar que, oficializada na grade curricular brasileira por uma Reforma articulada por Rui Barbosa, em 1854, a qual sugeriu essa disciplina como componente do currículo nacional, a Educação Física, inicialmente, teve sua prática fundamentada no alcance de aptidões físicas por meio de exercícios ginásticos aplicados segundo os interesses das classes que a exploravam. Dessa forma, os médicos utilizavam suas atividades com o propósito de desenvolver cuidados higiênicos necessários a um progresso civilizatório pela formação de uma população forte e saudável; os políticos e militares, as direcionavam para disciplinar o corpo e a moral, visando a manutenção da ordem política e o preparo físico para a força de trabalho; enquanto uma parcela de educadores enfatizavam sua atuação destinada à formação humana. Na proximidade à década de 1970, os esportes predominaram como conteúdo da Educação Física com um caráter de busca ao alto rendimento das habilidades motoras, em meio a um governo ditatorial militar que almejava a formação de atletas para a representação do país e a alienação da população às questões políticas vigentes (CASTELLANI FILHO, 1991; LINHALES, 2009; GÓIS JUNIOR, 2013).

Submetida a uma exploração fundamentada na padronização de corpos e funções para o alcance do alto rendimento, a Educação Física mantinha-se seletiva e excludente, não possibilitando relevante participação de pessoas que apresentassem características diferentes ao físico e funções almejados, dentre elas, a pessoa com deficiência (SILVA; ARAÚJO, 2012).

No entanto, a década de 80 trouxe consigo ideais transformadores com a ampliação do movimento de luta política pelos direitos humanos, inclusive da pessoa com deficiência, instigando o desencadear de ações legais que oficializaram uma proposta inclusiva no território nacional e em seus contextos sócio-educacionais.

Segundo Stainkback e Stainback (1999) e Silva, Seabra Júnior e Araújo (2008), o desenvolvimento dessa proposta ganhou força a partir do momento em que a exclusão pela qual essa população era submetida passou a ser questionada. Por conseguinte, desencadeou-se uma fase de "Normalização", onde se objetivou oferecer às pessoas com deficiência 
um padrão de vida próximo ao vivenciado na sociedade, ainda que de forma segregada em instituições especiais. Na sequência, essa fase absorveu uma ideia de "Integração", almejando preparar essas pessoas para também serem inseridas nos diferentes cenários sociais, se assim se mostrassem aptas. Com críticas sobre a forma como esta integração vinha acontecendo, com dificuldades em adaptar a pessoa ao ambiente, foi originado um movimento favorável à "Inclusão", propondo uma adequação da sociedade para que todos participassem de suas atividades, funções e ambientes. Cada uma dessas três etapas não findou as suas fases antecedentes, mas estimularam a superação de uma parte delas e a abertura para que novos ideais e ações mais humanas pudessem se propagar.

Permeado por essas discussões, no cenário educacional, foi elaborada a "Declaração de Salamanca", durante a "Conferência Mundial de Educação Especial", na Espanha, em 1994, sugerindo a educação inclusiva como uma educação na qual as escolas recebem e proporcionam alta qualidade de ensino a todas as crianças, independente das dificuldades e diferenças por estas apresentadas, atribuindo à própria escola a responsabilidade em adaptar a sua estrutura física, material, humana e pedagógica para isso. Essa sugestão foi acata pelo cenário brasileiro por meio da promulgação de documentos como a Lei de Diretrizes e Bases da Educação, de 1996 (BRASIL, 1994, 1996).

Nesse período, imersa e ao mesmo tempo abarcando as reconstruções sociais inclusivas implantadas, Bracht (1999) e Darido (2003) identificaram a ocorrência de uma reconstrução da Educação Física enquanto campo científico, com a redefinição de seu objetivo, finalidade e forma de atuação escolar em direção ao apontado no início desse texto.

Esse movimento renovador da área foi estruturado pela elaboração de abordagens, por vezes diferentes em seus objetivos, mas cada qual contribuindo com reflexões inovadoras aos poucos incorporadas pela Educação Física. Dentre elas, destaca-se a Desenvolvimentista, definindo uma primeira finalidade para a área, sendo ela o desenvolvimento e a aprendizagem motora; a Sistêmica, compreendendo a Educação Física como um conjunto de dimensões em interação entre si, defendendo a participação de todos nas aulas e implantando o princípio da não-exclusão; a Crítico-Superadora, sugerindo como conteúdo os relacionados à cultura corporal e criando uma metodologia de aula fundamentada no desenvolvimento crítico e autônomo do aluno acerca do contexto social e histórico cultural; a Teoria Crítico- Emancipatória, redefinindo o campo abarcado pela área como pertencente à cultura corporal de movimento fundamentado no "se movimentar", ou seja, centrada no indivíduo que realiza um movimento e no significado deste para o aluno; e a Cultural, a qual, em uma perspectiva antropológica, enfatizou a necessidade de uma Educação Física que considerasse as dimensões histórica, biológica, cultural, psicológica e social ao trabalhar com seus conteúdos, permitindo a participação de todos os alunos nas aulas, sem qualquer tipo de discriminação (COLETIVO DE AUTORES, 1992; DAOLIO, 1996; KUNZ, 2005; SILVA; SEABRA JUNIOR; ARAÚJO, 2008).

Nota-se que o cenário acadêmico reconstruiu a Educação Física também enquanto área inclusiva, abarcando, aos poucos, as diferentes dimensões e características dos alunos, com respeito e consideração a sua participação nas aulas. 
Contudo, as transformações de uma prática excludente para uma adaptada às diferentes necessidades do alunado parecem ainda estar em construção, conforme apontamentos apresentados pelos estudos referentes a essa temática. Prestes (2013) afirmou que o modelo de planejamento pedagógico e a própria infraestrutura educacional, atualmente oferecidos, ainda necessitam de reorganização, pois não tem se mostrado acessíveis nem adaptados a essa nova realidade inclusiva. Cunha e Silva (2013), assim como Fiorini e Manzini (2014), especificaram essa questão, descrevendo que os professores ainda possuem dificuldades no desenvolvimento de um planejamento dos conteúdos, dos métodos e das estratégias das aulas de forma inclusiva, empregando atitudes fundamentadas na improvisação, segundo as necessidades que se apresentam no decorrer da aula. O estudo de Seabra Junior (2012) confirmou tais entendimentos ao mostrar que os sentimentos presentes na fala geral dos professores são de impotência, insegurança e desconforto para atuar com a população com deficiência. Consequentemente, Salerno e Araújo (2004) elucidaram que, durante as aulas de Educação Física nas escolas regulares, ainda existem relatos da dispensa daqueles que apresentam deficiência, ou da participação passiva desses alunos, como ao atuarem como espectadores ou apenas auxiliares.

Observa-se, por conseguinte, que esses estudos acima apresentados têm destacado dificuldades relacionadas, principalmente, às questões de acessibilidade à instituição e aos seus recursos educacionais e de infraestrutura; à exploração dos conteúdos da disciplina conforme a redefinição proporcionada pelo movimento renovador da área; e também referentes às atitudes dos atores pertencentes à cena da educação inclusiva.

Quanto à acessibilidade, esta é assegurada e definida pela Lei $\mathrm{n}^{\circ} 10.098$, de 2000, como a "possibilidade e condição de alcance para utilização, com segurança e autonomia, dos espaços, mobiliários e equipamentos urbanos, das edificações, dos transportes e dos sistemas e meios de comunicação", devendo ser promovida em todos os espaços e equipamentos públicos nacionais (BRASIL, 2000, p. 01). Uma instituição física e materialmente acessível interfere decisivamente na chegada e permanência do aluno na instituição escolar.

Já os conteúdos que compõe a Educação Física foram definidos como aqueles relacionados aos movimentos corporais construídos e transformados pelo homem durante o decorrer histórico como forma de representação de sua realidade, com significação humana e sociocultural, sendo os principais a Dança / Atividades Rítmicas e Expressivas, o Esporte, a Ginástica, o Jogo e a Luta (COLETIVO DE AUTORES, 1992; BRASIL, 1998). Ao desenvolver esses temas no ensino escolar, a abordagem do Coletivo de Autores (1992, p. 87) orientou que:

[...] os conteúdos da cultura corporal a serem aprendidos na escola devem emergir da realidade dinâmica e concreta do mundo do aluno. Tendo em vista uma nova compreensão dessa realidade social, um novo entendimento que supere o senso comum, o professor orientará, através dos ciclos, uma nova leitura da realidade pelo aluno, com referências cada vez mais amplas.

As atitudes, por sua vez, segundo Coll et al. (1998), envolvem elementos cognitivos, afetivos e de conduta, ou seja, abarcam conhecimentos, crenças, sentimentos, ações e 
intenções. Dessa forma, estão relacionadas ao docente, para organizar os conteúdos e suas aulas de forma adequada às diferentes necessidades e capacidades dos alunos, englobando aspectos referentes à formação inicial, experiência profissional e até fatores pessoais. Esses elementos associam-se, também, à forma de interação dos alunos uns com os outros, as quais devem ser estimuladas a ocorrerem de forma respeitosa às diferenças para contribuir com a boa qualidade de participação de todos nas atividades da aula.

Nesta conjuntura, mostra-se necessário uma investigação dos fatores destacados nesse contexto para a compreensão das barreiras encontradas pelos alunos com deficiência para a sua inserção nas práticas pedagógicas da Educação Física Escolar. Por conseguinte, esse estudo objetivou analisar a percepção de professores de Educação Física Escolar sobre os elementos da tríade acessibilidade-conteúdos-atitudes em relação à inclusão de alunos com deficiência em suas aulas.

A percepção docente possibilita uma reflexão sobre a sua prática, sendo uma oportunidade de identificar dificuldades e ponderar sobre possibilidades de caminhos a serem percorridos. Dessa forma, permite ao pesquisador analisar uma realidade de forma concomitante a uma instigação de reconstrução da prática docente.

Para isso, esse estudo foi estruturado em três fases. Inicialmente, no tópico "Material e Métodos", foram especificados os procedimentos metodológicos empregados para o desenvolvimento do mesmo, assim como o instrumento utilizado. Posteriormente, em "Resultados e Discussão" foram apresentados os dados referentes às percepções citadas pelos docentes com subsequente reflexão com apoio da literatura existente e, em "Conclusões", as principais considerações obtidas foram reunidas e apresentadas.

\section{MATERIAL E MÉTODOS}

Esse estudo foi aprovado pelo Comitê de Ética da Unicamp, sob o número de parecer 812/2011. Caracterizou-se como pesquisa qualitativa por um estudo de caso, no qual, com uma análise predominantemente descritiva e interpretativa, um grupo é delimitado dentro de um ambiente amplo para ter suas características investigadas, visando uma compreensão de dada realidade e sua possível forma de ocorrência na sociedade (LUDKE; ANDRÉ, 1986).

Dessa forma, foi selecionada a cidade de Franca para ser investigada a percepção de seus docentes de Educação Física a respeito do processo inclusivo de alunos com deficiência em suas aulas. Este município foi selecionado pela maior facilidade de contato por parte dos pesquisadores, o que proporciona maior possibilidade de aceitação e participação dos docentes no estudo, culminando na obtenção de dados mais completos. A delimitação de uma localidade para ter suas características investigadas proporciona uma reflexão da implantação de um tema acadêmico na realidade, podendo auxiliar na compreensão do fenômeno, de forma geral, na sociedade, sem desconsiderar as peculiaridades de cada cenário. 
A cidade em questão está localizada na região nordeste do estado de São Paulo, a 401 quilômetros da capital. Com uma população estimada em 339.461 habitantes, mantém atividade econômica predominante na indústria da produção de calçados masculinos. Possui 26 escolas municipais de Ensino Infantil e 38 escolas municipais de Ensino Fundamental, contando com 56 professores de Educação Física. É considerada uma cidade universitária por conter instituições de ensino técnico e superior (PORTAL DE FRANCA, 2016).

Como procedimentos metodológicos, inicialmente foi contatada a Secretaria de Educação de Franca, solicitando autorização para um encontro com os professores de Educação Física das suas escolas municipais durante uma reunião pedagógica que seria realizada pelo Centro de Formação Continuada da Rede Municipal de Franca - núcleo organizado pela prefeitura da cidade com o objetivo de oferecer formação continuada e assessoria aos professores municipais. Com autorização concedida, durante essa reunião, a pesquisa foi apresentada aos professores, convidando-os a participarem. Aos que aceitaram, foram entregues e assinados os Termos de Consentimento Livre e Esclarecido e, posteriormente, o instrumento a ser preenchido por cada um deles a respeito da sua percepção sobre como tem ocorrido a inclusão de alunos com deficiência nas suas aulas. O instrumento foi apresentado aos professores pelo pesquisador desse estudo, o qual permaneceu à disposição antes, durante e após o preenchimento para possíveis esclarecimentos.

O instrumento utilizado foi o "Instrumento de avaliação da interação entre alunos com e sem deficiência na Educação Física Escolar" (SALERNO, 2009). Tendo por finalidade avaliar o processo inclusivo educacional, é constituído por 4 eixos temáticos que são ponderados pelo respondente quanto a sua existência/ocorrência, ou não, sendo eles:

- Acessibilidade: referente à presença de estruturas físicas específicas da escola, como locais e equipamentos adaptados e presença de sinais sonoros e visuais;

- Conteúdos da Educação Física: englobando aspectos relacionados ao tipo de conteúdo trabalhado e sua forma de exploração pelo professor (competitiva ou cooperativa, como vivência ou treinamento, em grupo ou individual, com materiais adaptados e uso de textos e pesquisas na internet ou não).

- Atitudes e estratégias do professor durante o tempo das aulas: se o professor elaborou as aulas de forma a permitir a participação de todos, se incentivou ou auxiliou o aluno com deficiência fisicamente, se estimulou a cooperação e o diálogo entre os alunos, se ouviu a opinião de todos, se infantilizou ou colocou como auxiliar ou em atividade paralela o aluno com deficiência.

- Atitude do aluno com deficiência: se participou das atividades e se essa participação ocorreu de forma ativa ou passiva, se houve afastamento deste da atividade por iniciativa própria ou por sugestão do professor e se houve aceitação do aluno em permanecer nessa situação, se expôs suas ideias, se interagiu com os demais de forma positiva ou negativa, se respondeu às iniciativas de interação dos colegas, se solicitou auxilio aos professores ou colegas para a realização das atividades e se apresentou prontidão para participar das aulas.

- Atitude dos alunos sem deficiência: se iniciaram ou responderam às interações iniciadas pelos alunos com deficiência de forma positiva ou negativa, se infantilizaram, auxiliaram ou fizeram a atividade no lugar deste aluno. 
O instrumento passou por validação de face e semântica, processo destinado a sua verificação quanto ao alcance das finalidades às quais se propôs.

Os dados obtidos foram analisados por categorização a qual, segundo Ludke e André (1986), refere-se à organização dos mesmos em categorias ou temas de análise. Foram, por conseguinte, definidas as categorias que compõe a tríade aqui analisada: acessibilidade, conteúdos da Educação Física explorados nas aulas e atitudes dos docentes e alunos.

\section{RESULTADOS E DISCUSSÃO}

De um total de 56 professores de Educação Física, 36 consentiram em participar da pesquisa. As respostas foram agrupadas em três categorias, sendo que o professor pode citar mais de um item em cada uma delas. A primeira refere-se aos artefatos de acessibilidade:

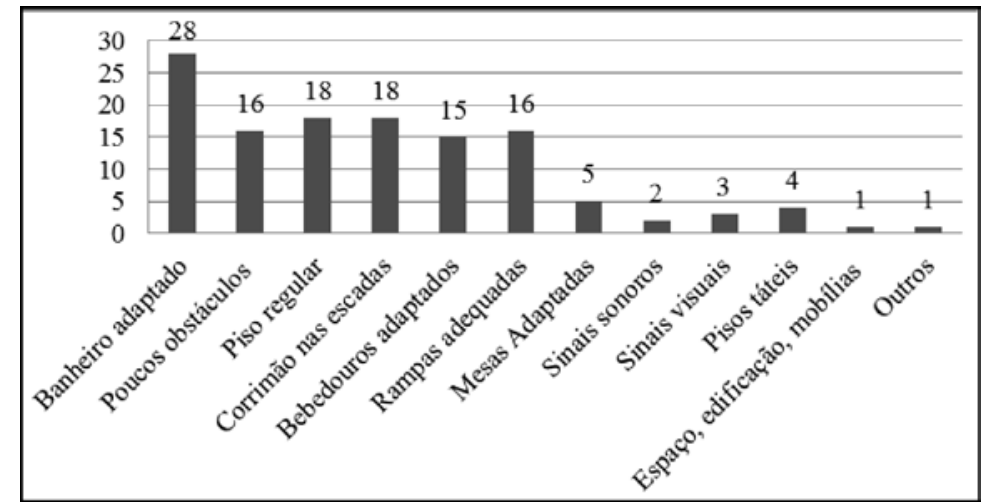

Figura 1 - Itens de acessibilidade presentes nas escolas em que atuam os professores entrevistados.

Em relação à acessibilidade arquitetônica das escolas, os professores perceberam a existência apenas dos itens de necessidade básica mais comumente conhecidos, como corrimão nas escadas, banheiros e bebedouros adaptados. Essa fragilidade estrutural também foi verificada por Gorgatti e Rose Junior (2009), os quais evidenciaram, em uma pesquisa com professores de escolas particulares e públicas, que todos afirmaram que suas instituições ainda não estão totalmente preparadas quanto à estrutura física para a recepção de alunos com deficiência. Tais dados encontram justificativa no estudo de Carvalho (2014), a qual afirmou que a acessibilidade das escolas ainda apresenta-se constituída, predominantemente, por itens rotineiramente encontrados, como rampas e corrimões nas escadas, sendo os demais inseridos apenas conforme os alunos com essas condições específicas vão chegando às instituições, e não antecedente a essa inserção.

Verifica-se, nessa primeira categoria, a percepção de uma atitude passiva nas diversas instâncias tanto públicas, conforme verificado nesse estudo, quanto particular, segundo 
apontado na pesquisa acima citada, que aguardam as ocorrências para adequarem-se às demandas apresentadas por um grupo específico que a cada dia amplia sua participação na sociedade, apropriando-se de seus direitos.

Já na segunda categoria, foram relatados os conteúdos que têm sido explorados pelos docentes, assim como as estratégias empregadas durante o trabalho com os mesmos:

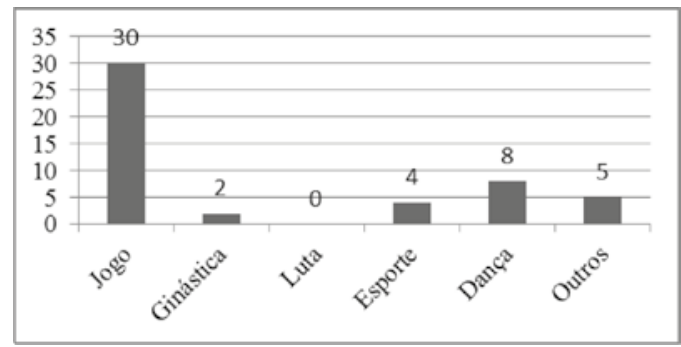

Figura 2 - Conteúdos da Educação Física explorados durante as aulas.

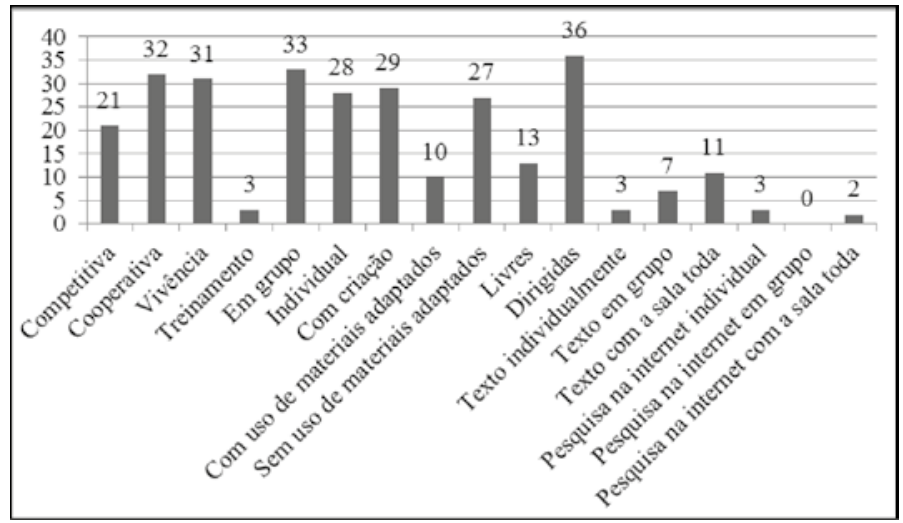

Figura 3 - Estratégias empregadas pelos docentes de Educação Física em suas aulas.

Analisando os dados obtidos na segunda categoria desta tríade investigada - conteúdos trabalhados durante as aulas -, o jogo foi citado como conteúdo de presença predominante durante as aulas já ministradas, e a luta como um conhecimento negligenciado pelos docentes.

Sobre essa questão, Carvalho (2014) também notou a prevalência dos conteúdos de jogo e, na sequência, esporte sobre os demais; citou ainda a falta de segurança dos próprios professores em abordarem os diversos temas devido a uma formação acadêmica precária fundamentada, principalmente, no contexto esportivo, além da dificuldade docente em lidar com a resistência dos próprios alunos em explorarem conteúdos diferentes dos comumente vivenciados nas últimas décadas. 
Silva e Silva (2015), questionando alunos do Ensino Fundamental, anos finais, sobre os conteúdos vivenciados na Educação Física, também encontram o enfoque dados às quatro modalidades esportivas coletivas de basquete, handebol, futebol e vôlei.

Por sua vez, Seabra Júnior e Araújo (2008) corroboraram com essa discussão ao afirmarem que, em muitos momentos a própria escolas restringe as possibilidades de trabalho do docente, ao ainda exigirem um empenho em quantidade excessiva de tempo para a organização de eventos esportivos e competições.

Pode-se associar tal resultado como consequência de fatores relacionados à construção histórica da Educação Física, onde uma fase de esportivização foi vivenciada em décadas anteriores induzindo à maciça presença de esportes, e também de jogos destinados ao aprendizado esportivo, tanto nas escolas regulares como nos cursos de formação docente, o que ainda se reflete na prática atual. Denota-se que os professores de Educação Física têm percebido resquícios da anterior atuação da Educação Física Escolar Esportivadora, sendo ainda tímida a reconstrução da área fundamentada nas novas abordagens elaboradas. Sabendo que essas novas abordagens romperam com a anterior exclusão dos menos habilidosos em prol de uma Educação Física humana, global e permissiva da participação de todos, a manutenção desses vestígios históricos pode dificultar a construção de uma aula respeitosa e acolhedora das diversidades. Dessa forma, a abertura docente para uma reflexão direcionada à reconstrução de sua prática segundo as novas propostas acadêmicas pode ser um caminho favorável também para a efetivação de uma prática inclusiva.

Nesse momento, não se nega a importância do jogo ou do esporte enquanto conteúdos educacionais, mas sim a ausência de todas as outras possibilidades de vivências, a qual prejudica a construção de conhecimentos assim como de possibilidades de reconstruções sócioculturais dos alunos a respeito dos temas. Betti e Zuliani (2002) destacaram, nesse contexto, que durante uma aula de Educação Física Escolar torna-se indispensável que o professor siga alguns princípios que podem favorecer a inclusão, como a própria exploração da diversidade de conteúdos, uma vez que esta propicia maiores possibilidades de desenvolvimento das múltiplas capacidades dos alunos bem como de identificação de conteúdos com os quais os alunos mais se identifiquem, compreendendo que em cada conteúdo, diferentes dificuldades ou facilidades aparecerão, além de que, mesmo que apresente dificuldade em um momento, pode se destacar pelas suas capacidades em outro.

Por outro lado, se a seleção dos conteúdos se mostrou resistente às mudanças e prejudicial à construção inclusiva, as estratégias empregadas pelos docentes aparentaram ser a porta de entrada para a modificação da área em direção à inclusão. Os docentes relataram utilizar todas as estratégias citadas no questionário, com exceção da pesquisa em grupo com a utilização da internet. Abre-se uma reflexão sobre uma possibilidade de início de reconstrução da Educação Física no cenário escolar por meio de uma nova atuação que vem sendo desempenhada pelos docentes de forma consciente às diversas possibilidades metodológicas da área e da responsabilidade do professor enquanto mediador desse processo educacional.

O direcionamento do educador deve possibilitar aos alunos não só a construção de conhecimento bem como a sua possível reconstrução com autonomia e exploração dos 
ideais de respeito e de cidadania. Com isso, ampliam-se as possibilidades de estabelecer positivamente as diversas facetas do processo inclusivo.

Tais elementos podem influenciar a terceira categoria analisada - atitudes entre os atores da inclusão educacional (Figura 4) -, uma vez que uma aula com emprego de estratégias competitivas, sem direcionamento educativo, pode afastar ou até mesmo impedir a participação de alunos que apresentarem dificuldades na modalidade em específico, influenciando negativamente a inclusão de todos nas aulas; já uma atividade que estimule o respeito e a cooperação, ainda que competitiva, auxilia na construção de relações afetuosas, superação das dificuldades e aceitação das diferenças.

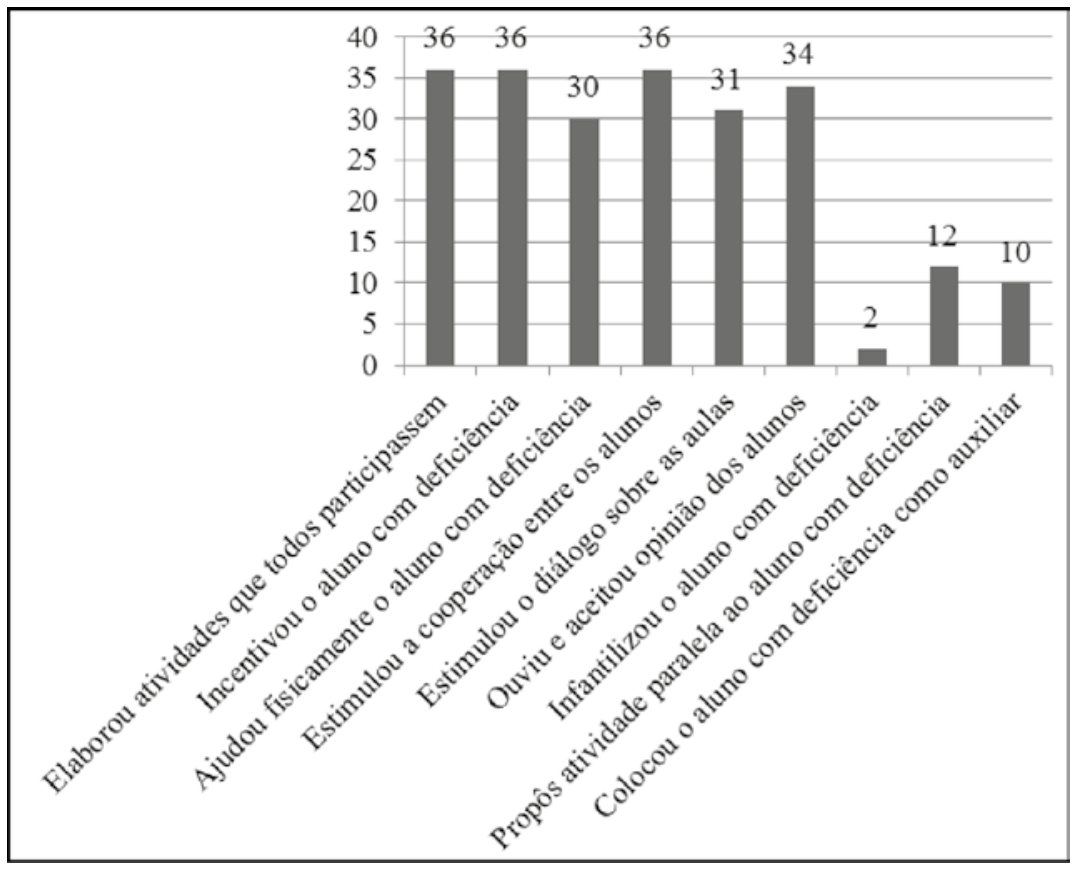

Figura 4 - Atitude do professor de Educação Física em relação aos alunos com deficiência.

Em relação aos dados concernentes à atitude dos docentes, todos disseram considerar, no seu planejamento e execução de aulas, formas de propiciar a cooperação e a participação dos alunos, inclusive dos que apresentam condições de deficiência. Apesar de este relato ser positivo, algumas citações mostraram a permanência de atitudes não consonantes com os ideais inclusivos, como a infantilização de alunos com deficiência, sua alocação em atividades separadas do grupo ou apenas como auxiliador deste e a escassez na estimulação de diálogo entre os alunos. Tal fato corrobora com o encontrado por Salerno e Araújo (2004), os quais mostraram a manutenção de atitudes docentes conduzindo esses 
alunos a participarem de forma paralela, realizando atividades em conjunto com a turma toda apenas em alongamentos e aquecimentos.

Especificamente em relação à ausência de diálogo, esse fator também dificulta a construção de conhecimentos sobre as diferenças apresentadas pelos alunos, fator inicial e indispensável para o posterior respeito e aceitação das mesmas.

Cabe destacar, também, a indicação, pelos docentes, da ocorrência de infantilização para com os alunos com deficiência. Essa ocorrência atua como uma barreira atitudinal à inclusão, podendo dificultar o desenvolvimento da autonomia e independência dessas pessoas, impedindo sua vivência motora, psicológica e sócio-cultural, além de esse tipo de barreira contribuir com a formação de preconceitos (LIMA; SILVA, 2008).

Notando que esses equívocos apareceram nos questionários de forma discreta, pode-se verificar que os professores estão vivenciando um processo de adequação das suas aulas e de sua forma de atuação com as diferentes necessidades e condições apresentadas pelos discentes, assim como de construção de conhecimentos sobre as diversidades.

Essas questões podem estar relacionadas às dificuldades do professor em lidar com a diferença do movimento desejado e do movimento encontrado, ou seja, ao longo da formação profissional estuda-se o desenvolvimento motor baseado em pessoas sem deficiência, em gestos técnicos envolvendo modalidades esportivas convencionais, planejam-se aulas sem considerar as diferentes habilidades. Fato é que, quando alcançamos o chão da escola, nos deparamos com a diversidade de interesses, habilidades e conhecimentos prévios, cabendo ao docente o papel de adequação das atividades e propostas, o que pode gerar desconforto e insegurança. Amaral (1994) ressaltou que esse processo inicial de contato do professor com a pessoa com deficiência, confronta o ideal de aluno, de aula e de movimento desenvolvido durante a sua formação, não compatível com a realidade encontrada.

O que queremos deixar claro é que essa diferença em hipótese alguma se mostra negativa, porém, pode causar iniciais entraves para a efetivação do processo de inclusão da pessoa com deficiência. Nesse sentido, Mendonza Laís (2008) confirmou essa dificuldade docente em lidar com a diversidade, uma vez que, em seu estudo, a heterogeneidade das classes da escola regular foi incorporada pelos professores pesquisados aos fatores dificultadores do processo inclusivo, juntamente com recursos materiais e humanos. Sem dúvida, esse é um aspecto que permeia a Educação Física Escolar há tempo, haja vista que a diversidade não se apresenta apenas com quadros de condições de deficiência. Entretanto, as diferentes habilidades em pessoas que não possuem uma condição de deficiência não se destacam, ou seja, um aluno pode passar a aula toda sem participar efetivamente da aula, mas estando junto com seus colegas. Para um olhar desavisado isso se configura como participação. Já a exclusão da pessoa com deficiência salta aos olhos, se um aluno utilizador de cadeira de rodas aloca-se ao canto da quadra sua não inclusão se sobressai. Deparamo-nos, então, com um destacamento de uma exclusão que por anos foi apenas velada.

Fato que pode contribuir para a superação dessas dificuldades, segundo Venditti Jr (2010) e Hernández Vázquez, Ródenas e Niort (2012), é a experiência envolvendo a pessoa com deficiência. Segundo os autores, as reflexões geradas a partir de vivências 
envolvendo essa população podem colaborar com a busca de soluções frente à diversidade de habilidades, tanto nos cursos de formação docente quanto com os próprios alunos da escola regular.

Prosseguindo a discussão, foi ainda registrado a percepção docente das atitudes desempenhadas tanto pelos alunos com deficiência quanto pelos alunos sem essa condição:

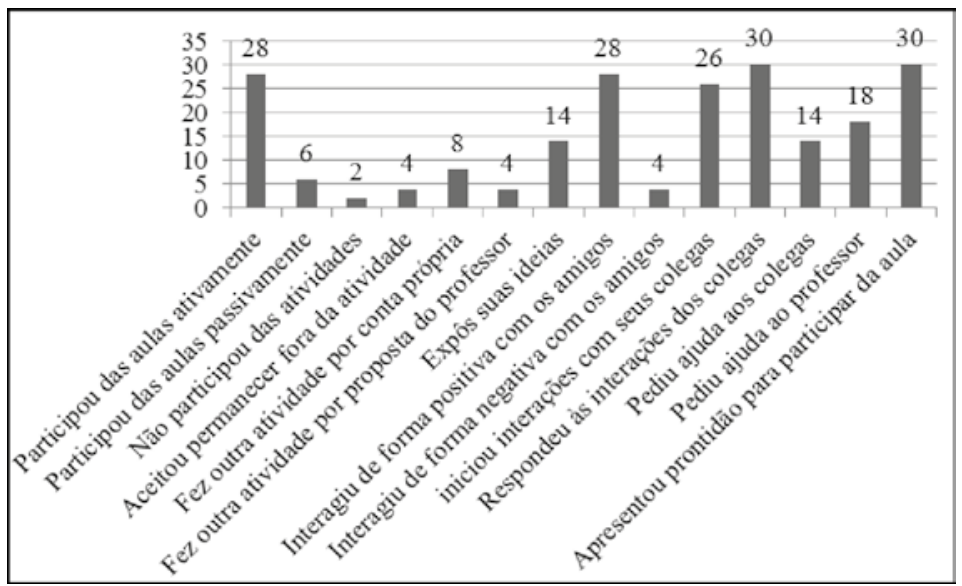

Figura 5 - Interação do aluno com deficiência durante as aulas.

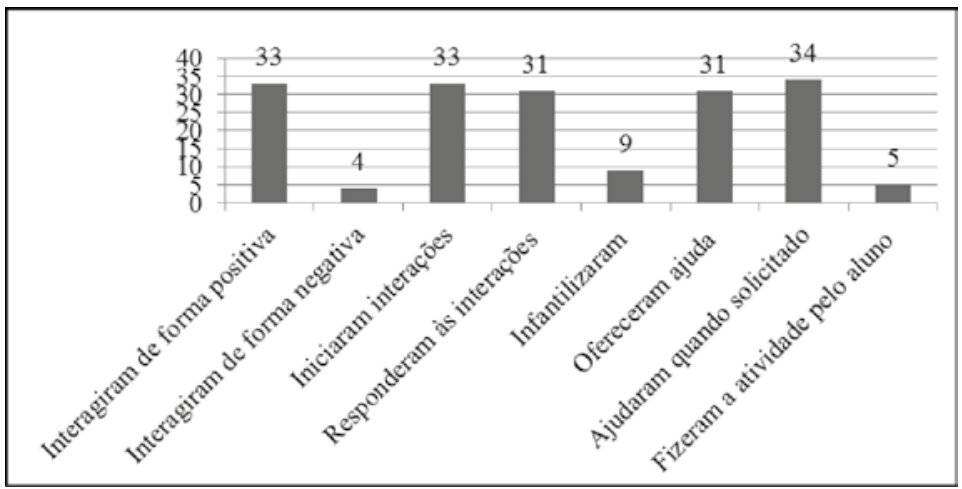

Figura 6 - Interação dos colegas sem deficiência em direção ao aluno com deficiência.

Pela apreciação dos dados apresentados, as interações realizadas entre os alunos apresentam-se, em sua maioria, ocorrendo de forma positiva, com a participação efetiva do aluno com deficiência durante as aulas, o qual tem procurado por e respondido às interações dos demais alunos da sala. Tal resultado possui relevância incomensurável ao considerarmos que proporcionar interações positivas entre todos da sala facilita o processo 
de construção da inclusão educacional, já que conviver e interagir com as diferenças é uma das principais formas de auxiliar na superação do estranhamento em relação às condições de deficiência e de desenvolver o respeito e a aceitação das mesmas (SALERNO, 2009).

Apesar de predominantemente positivas, algumas interações negativas também foram mencionadas. Contudo, adversidades fazem parte tanto do contexto educacional quanto das interações sociais, sendo uma possibilidade rica de direcionamento educativo ao orientar como superá-las e solucioná-las.

O estudo desenvolvido por Carvalho (2014) encontrou resultado semelhante também neste item, mostrando a existência de interações predominantemente positivas entre alunos com e sem deficiência nas aulas de Educação Física, sendo as interações negativas escassas, mas, quando as mesmas ocorrem, parecem ter associação com as estratégias e atividades empregadas pelo professor, sendo desencadeadas por atividades de caráter competitivo com ênfase na vitória e sem orientação educacional a respeito dos aspectos da competição. Esses relatos autenticam a discussão acima apresentada mostrando, de fato, que o contexto da aula é influenciador das interações sociais vivenciadas durante a Educação Física Escolar.

Visualiza-se, por fim, no quadro fornecido por esses docentes, que a cidade foco desse estudo tem caminhado por um momento de reconstrução no cenário da Educação Física em direção ao alinhamento às políticas inclusivas. Dessa forma, avanços são notados como a atenção destinada pelos professores à elaboração de aulas participativas para todos, concomitantemente à permanência de ainda alguns entraves, como a precariedade de diálogo entre todos para a construção da proposta inclusiva.

Esse resultado encontra-se em consonância com estudos elaborados sobre essa temática. Rechinelli (2008) concluiu, em pesquisa analisando o discurso dos professores de Educação Física Escolar do município de Itapetininga a respeito da inclusão de pessoas com deficiência, que estes têm buscado capacitação para construir a inclusão em suas aulas, mostrando uma fase de identificação de dificuldades e posterior busca por soluções por parte desses profissionais, alternando dificuldades e avanços na construção do processo inclusivo. Complementarmente, Abreu (2009) identificou que a ausência de organização das aulas e a identificação de dificuldades têm sido substituídas, ainda que vagarosamente, por uma fase de planejamento e sistematização das mesmas, já considerando a participação de alunos com características diferenciadas.

Por sua vez, a pesquisa de Souza (2013) confirmou a crença na possibilidade de incluir alunos com deficiência na Educação Física Escolar com qualidade de ensino, respeitando suas limitações e desenvolvendo suas possibilidades. Tal objetivo mostrou ser possível por meio do emprego de métodos de ensino apropriados, associação da prática com um referencial teórico de suporte, existência de uma equipe interdisciplinar atuando conjuntamente, adequação de recursos materiais e disposição de acolhimento pelos profissionais, revendo o processo de ensino-aprendizagem, repensando a exploração dos espaços e tempos da escola e investindo na formação continuada.

Frente aos dados registrados e discutidos nesse estudo, identificamos alguns fatores necessários de serem revistos pelas políticas públicas e instituições escolares: 
- Analisar mais detalhadamente a acessibilidade das instituições, para a incorporação de todos os itens que a compõe de forma antecessora à chegada dos alunos;

- Desenvolver programas de atualização profissional docente, explorando conhecimentos a respeito dos processos educacionais inclusivos com as diversas condições de deficiência;

- Necessidade de capacitação docente em relação à renovação da atuação da Educação Física Escolar, explorando a diversificação dos conteúdos de Educação Física;

- Explorar, com os alunos, formas de interação e de auxílio aos alunos com deficiência, em substituição à infantilização e à superproteção.

\section{CONCLUSÕES}

Ao analisar os dados obtidos nessa realidade específica foram notados dois pontos complementares: se por um lado a riqueza dos dados fornecidos pelos professores dessa rede municipal permitiu um olhar positivo sobre as ações presentes, por outro, apontou elementos que necessitam de aprofundamentos. Dessa forma, foi verificado:

- Acessibilidade: ainda encontra-se em construção conforme as necessidades despontam, com as instituições educacionais possuindo apenas itens de necessidade básica mais comumente conhecidos, como corrimão nas escadas, banheiros e bebedouros adaptados;

- Conteúdos: alguns fatores tem prejudicado a inclusão de alunos com deficiência, como a manutenção da predominância do jogo e esporte, decorrente de um possível resquício histórico onde a área foi direcionada às atividades esportivas; mas outros a tem favorecido como a implantação de diversidade de estratégias de ensino empregadas pelos professores em suas aulas;

- Atitudes: há a ocorrência de um processo de adequação das atitudes conforme se tem ampliado os conhecimentos acerca das diversidades, com professores buscando permitir a participação de todos, mas ainda alocando-os à posição de auxiliar ou em atividade paralelas em alguns momentos; já os alunos têm predomínio de interações positivas entre si, com conflitos inerentes ao contexto educacional e infanto-juvenil. Observou-se, por fim, que as dificuldades de consolidar a inclusão na Educação Física Escolar não podem ser atribuídas apenas às dificuldades de trabalhos específicos com pessoas com alguma condição de deficiência, mas refletem um contexto histórico da Educação Física no qual a heterogeneidade foi negada em busca de um padrão físico e motor almejado. Necessita-se, nesse momento, de continua abertura da prática docente às reflexões proporcionadas pelo campo acadêmico tanto de propostas para a área da Educação Física Escolar quanto para fundamentar a prática docente adequada para as diversidades apresentadas pelos alunos. 


\section{REFERÊNCIAS}

ABREU, J. R. G. de. Inclusão na educação física escolar: abrindo novas trilhas. 2009. 152f. Dissertação (Mestrado em Educação Física) - Centro de Educação Física e Desportos, Universidade Federal do Espírito Santo, Vitória, 2009.

BETTI, M.; ZULIANI, L. R. Educação Física Escolar: uma proposta de diretrizes pedagógicas. Revista Mackenzie de Educação Física e Esporte, São Paulo, v.1, n.1, p. 73-81, jan./ dez. 2002.

BRACHT, V.. A constituição das teorias pedagógicas da educação física. In: Caderno Cedes. Ano XIX, n. 48, p. 69-88, ago. 1999.

BRASIL. Constituição da República Federativa do Brasil: promulgada em 5 de outubro de 1988. 4. ed. São Paulo: Saraiva, 1988.

. Declaração de Salamanca. Sobre Princípios, Politicas e Práticas na Área das

Necessidades Educativas Especiais. Brasília, DF, 1994. Disponível em: < http://www.portal. mec.gov.br >. Acesso em: 25 mar. 2016.

. Lei de Diretrizes e Bases da Educação Nacional. Lei no 9394, de 20 de dezembro de 1996. Estabelece as diretrizes e bases da educação nacional. Brasília, DF, 1996. Disponível em: < http://www.portal.mec.gov.br>. Acesso em: 10 jan. 2016.

. Parâmetros curriculares nacionais: Educação física. Secretaria de Educação Fundamental. Brasília: MEC/SEF, 1998. Disponível em: < portal.mec.gov.br/seb/ arquivos/pdf/fisica.pdf>. Acesso em: 27 mar. 2017.

. Lei no. 12.796, de 4 de abril de 2013. Altera a Lei $n^{\circ}$ 9394, de 20 de dezembro de 1996. Brasília, DF, 2013. Disponível em: < http://www.planalto.gov.br/ccivil_03/_ Ato2011-2014/2013/Lei/L12796.htm\#art1 > . Acesso em: 05 abr. 2016.

CARVAlho, C. L. Conteúdos da educação Física e a Pedagogia de Freinet: Pintando uma possibilidade para o aluno com Síndrome de Down. 2014. 197f. Dissertação (Mestrado em Educação Física)-Faculdade de Educação Física, Universidade Estadual de Campinas, Campinas, 2014.

CASTELLANI FILHO, L. Educação Física no Brasil: a história que não se conta. 2. ed. Campinas: Papirus, 1991.

COLETIVO DE AUTORES. Metodologia do Ensino da Educação Física. São Paulo: Cortez, 1992.

COLL, C.; et al. Os Conteúdos na Reforma: ensino e aprendizagem de conceitos, procedimentos e atitudes. Porto Alegre: Artes Médicas, 1998.

CUNHA, A. C. P. da; SILVA, A. P. S. da. Estudo bibliográfico sobre a inclusão do aluno com distrofia muscular de Duchenne nas aulas de educação física . In: Anais do XVIII Congresso Brasileiro de Ciências do Esporte (CONBRACE) / V Congresso Internacional de Ciências do Esporte (CONICE): Identidade da educação física e ciências do esporte em tempos de megaeventos. Brasília, 2013.

DAOLIO, J. Educação Física Escolar: em busca da pluralidade. Revista Paulista de Educação Física, São Paulo, supl.2, p. 40-42, 1996.

DARIDO, S.C. Educação física na escola: questões e reflexões. Rio de Janeiro: Guanabara Koogan, 2003. 
FILUS, J. F. Amarrações e arrumações na inclusão escolar do município de Hortolândia SP. 2011. 199f. Tese (Doutorado em Educação Física) - Faculdade de Educação Física, Universidade Estadual de Campinas, Campinas, 2011.

FIORINI, M. L. S.; MANZINI, E. J. Inclusão de alunos com deficiência na aula de educação física: identificando dificuldades, ações e conteúdos para prover a formação do professor. Revista Brasileira de Educação Especial, Marília, v.20, n.3, p. 387-404, jul./set. 2014.

GÓIS JUNIOR, E. Ginástica, higiene e eugenia no projeto de nação brasileira: Rio de Janeiro, século XIX e início do século XX. Movimento (UFRGS. Impresso), Porto Alegre, v. 19, n. 01, p. 139-159, jan./mar. 2013.

HERNÁNDEZ VÁZQUEZ, F.J.; RÓDENAS, A.B.; NIORTE, J. Cuáles son los retos de la inclusión en la clase de educación física? In: HERNÁNDEZ VÁZQUEZ (coord). Inclusión en educación física: las claves del éxito para la inclusión del alumnado com capacidades diferentes. Barcelona: INDE. 2012. p. 23 - 36.

JANNUZZI, G. A educação do deficiente no Brasil: dos primórdios ao início do século XXI. 2. ed. Campinas: Autores Associados, 2006.

KRUG, H. N. A inclusão de pessoas portadoras de necessidades educativas especiais na educação física escolar. In: Cadernos, $n^{\circ}$ 19, 2002. Disponível em: http://coralx.ufsm. br/revce/ceesp/2002/01/a3.htm > . Acesso em: 02 abr. 2016.

KUNZ, E. Didática da educação física: 2. 3. ed. Ijuí: Unijui, 2005.

LIMA, F. J.; SILVA, F. T. S. Barreiras atitudinais: obstáculos à pessoa com deficiência na escola. IN: SOUZA, O. S. H. Itinerários da inclusão escolar. Canoas: Ed. ULBRA; Porto Alegre: AGE, 2008.

LINHALES, M. A. Militares e educadores na Associação Brasileira de Educação: circulação de interesses em torno de um projeto para a educação física nacional (1933-1935). Educar em Revista, Curitiba, v. 33, p. 75-91, 2009.

LUDKE, M.; ANDRÉ, M. E. D. A. Pesquisa em educação: abordagens qualitativas. São Paulo: EPU, 1986.

MEIRELES-COELHO, C.; IZQUIERDO, T.; SANTOS, C. (2007). Educação para todos e sucesso de cada um: do Relatório Warnock à Declaração de Salamanca. In: SOUZA, J. M. Actas do IX Congresso da SPCE: Educação para o sucesso: políticas e actores. Porto: SPCE, 2007, p.178-189.

MIRANDA, A.A.B. Educação especial no Brasil: desenvolvimento histórico. Cadernos de história da educação, Uberlândia, n. 7, jan./dez. 2008.

PEDRINELLI, V. J. Possibilidades na diferença: o processo de 'inclusão', de todos nós. Integração, Brasília, v.4, ed. esp., p. 31-34, 2002.

PRESTES, D. B. Comportamento motor da criança com deficiência múltipla nos contextos vivenciais: um estudo de caso. 2013. 150f. Dissertação (Mestrado em Ciências do Movimento Humano) - Centro de Ciências da Saúde e do Esporte, Universidade do Estado de Santa Catarina, Florianópolis, 2013.

RECHINELI, A. O Fenômeno da inclusão na educação física escolar: o discurso dos professores de Itapetininga. 2008. 126f. Dissertação (Mestrado em Educação Física) - 
Faculdade de Ciências da Saúde, Universidade Metodista de Piracicaba, Piracicaba, 2008.

SALERNO, M. B. Interação entre alunos com e sem deficiência na educação física escolar: validação de instrumento. 2009. 124f. Dissertação (Mestrado em Educação Física) Faculdade de Educação Física, Universidade Estadual de Campinas, Campinas, 2009.

SALERNO, M.B.; ARAÚJO, P. F. Educação física escolar como espaço inclusivo. In: Movimento e Percepção, Espírito Santo do Pinhal, v.4, n. 4/5, p.01 - 12, jan./dez. 2004.

SEABRA JÚNIOR, L. Educação física e inclusão educacional: entender para atender. 2012. 111f. Tese (Doutorado em Educação Física) - Faculdade de Educação Física, Universidade Estadual de Campinas, Campinas, 2012.

SILVA, O. M. da. A pessoa deficiente na história do mundo de ontem e de hoje. São Paulo: CEDAS, 1987.

SILVA, R. de F. da; ARAÚJO, P. F. da. Os caminhos da pesquisa em atividade motora adaptada. São Paulo: Phorte, 2012.

SILVA, R. F.; SEABRA JUNIOR, L.; ARAÚJO, P. F. Educação física adaptada no Brasil: da historia à inclusão educacional. São Paulo: Phorte, 2008.

SILVA, J. V. P.; SILVA, L. L. G. Educação Física nos anos finais do Ensino Fundamental em Campo Grande/MS. Revista Brasileira de Ciência e Movimento, Taguatinga, v. 23, n. 2, p. 22-31, abr./jun. 2015. Disponível em: < https://portalrevistas.ucb.br/index.php/ RBCM/article/view/4607>. Acesso em: 14 nov. 2016.

SMITH, D. D. Introdução à educação especial: ensinar em tempos de inclusão. 5. ed. Porto Alegre: Artmed, 2008.

SOLER, R. Educação física inclusiva na escola: em busca de uma escola plural. Rio de Janeiro: Sprint, 2005.

SOUZA, F. A. de. Formação, educação física e inclusão: compreendendo os processos inclusivos. 2013. 112 f. Dissertação (Mestrado em Educação Física) - Centro de Educação Física e Desportos, Universidade Federal do Espírito Santo, Espírito Santo, 2013.

STAINBACK, S.; STAINBACK, W. Inclusão: um guia para educadores. Porto Alegre: Artmed, 1999.

VENDITTI JR, R. Auto eficácia docente e motivação para realização do (a) professor (a) de Educação Física Adaptada. 2010. s[f]. Tese (Doutorado em Educação Física) Faculdade de Educação Física, Universidade Estadual de Campinas, Campinas, 2010.

Recebido em: fevereiro/2017 Aprovado em: junho/2017 